UDC: $821.134(7 / 8) .09 \mathrm{Paz}$ O. DOI: https://doi.org/10.18485/beoiber.2019.3.1.4

\author{
Liliana Karina Alanís Flores ${ }^{1}$ \\ Universidad de Gdansk \\ Polonia
}

\title{
UN ANÁLISIS PRAGMÁTICO-SEMÁNTICO DE LA IRONÍA EN LOS ENSAYOS LITERARIOS DE OCTAVIO PAZ
}

\begin{abstract}
Resumen
En este trabajo se analizan algunos fragmentos de la obra ensayística de Octavio Paz. El análisis consiste en hacer una descripción pragmática de las obras, en la que se propone un estudio de la ironía como medio de argumentación lingüística, basado en dos importantes teorías: la teoría de la argumentación en la lengua de J.C Anscombre y O. Ducrot, y la teoría de la relevancia formulada por D. Sperber y D. Wilson. Para lograr este análisis se exponen perspectivas teóricas y se entrelazan en un marco teórico aplicable al análisis pragmático y semántico de los ensayos seleccionados.

Palabras clave: ironía, argumentación, pragmática, ensayo literario, Octavio Paz.

\section{A PRAGMATIC-SEMANTIC ANALYSIS OF IRONY IN OCTAVIO PAZ'S LITERARY ESSAYS}

\section{Summary}

In this paper we analyze a few fragments of Octavio Paz's literary essays. This analysis is aimed to propose a pragmatic-semantic study of specific utterances, which contains a study of irony as a linguistic argumentative instrument. The analysis is based on two main theories: on the one hand, the argumentation theory stated by Anscombre and Ducrot, and on the other hand, the relevance theory developed by Sperber and Wilson. The most important claims and concepts of each theory are presented in order to construct a suitable theoretical framework which allows us to describe different kinds of ironies and their argumentative and cognitive effects on readers.
\end{abstract}

Key words: irony, argumentation, pragmatics, literary essay, Octavio Paz.

\footnotetext{
${ }^{1}$ karina.alhaniz@gmail.com
} 


\section{Introducción}

El presente análisis parte de la idea de que la argumentación es un fenómeno lingüístico y cognitivo que se halla en cualquier forma de comunicación verbal; siguiendo lo establecido por la teoría de Anscombre y Ducrot (1994), es la lengua misma la que posee los elementos esenciales para lograr la comunicación. La argumentación es connatural al lenguaje mismo, y por ello partimos de que cualquier tipo de ensayo puede ser analizado no sólo a partir de sus aspectos estilísticos, sino también mediante la observación de sus mecanismos lingüísticos y pragmáticos. Este análisis de índole pragmático-semántico tiene como objetivo principal estudiar el fenómeno de la ironía como estrategia de argumentación lingüística. Para ello, la ironía se analiza desde dos perspectivas teóricas que nos pueden brindar panoramas diferentes para describir este fenómeno: la teoría de la argumentación en la lengua y la teoría de la relevancia. La tesis central de este trabajo es que, por medio de un análisis de los aspectos lingüísticoargumentativos de los textos elegidos será posible hallar diversos enunciados en los que la ironía funciona como un mecanismo argumentativo muy efectivo a la hora de comunicar ideas y para generar efectos cognitivos específicos en el lector. Durante este proceso de examinación de los diversos fragmentos, se observa el comportamiento de enunciados que se manifiestan evidentemente irónicos y de otros que pueden también tener los mismos efectos, pero que se presentan de una manera menos obvia. Siendo así, uno de los objetivos de este trabajo es presentar enunciados que pueden considerarse como irónicos analizando y especificando el porqué, cómo y en qué niveles puede funcionar la ironía en el discurso. En los siguientes apartados, se presenta una introducción breve a las teorías y los conceptos básicos para poder aplicarlos a la descripción de los textos seleccionados.

\section{Teoría de la Relevancia}

Dan Sperber y Deirdre Wilson (2004) proponen una teoría en la que el llamado principio de relevancia es una propiedad cognitiva innata del ser humano. La teoría de la relevancia surge como una teoría cognitiva-inferencial que pretende describir el proceso en el que el oyente abstrae el significado transmitido por su interlocutor a partir de los códigos contenidos en el enunciado. Para soportar su teoría, los autores hacen una revisión de las máximas de la conversación de Grice (1991); no obstante, se desmarcan del modelo por él propuesto, y consideran únicamente los siguientes aspectos:

I. La teoría de la relevancia puede entenderse como el intento de profundizar en una de las tesis fundamentales de Grice: que una característica esencial de la mayor parte de la comunicación humana es la expresión y el reconocimiento de intenciones. Con 
el desarrollo de tal tesis, Grice sentó las bases de un modelo inferencial de la comunicación, alternativo al modelo clásico del código. (Sperber y Wilson 2004: 238)

II. La teoría de la relevancia se basa también en otra de las tesis fundamentales de Grice: que las emisiones generan de manera automática una serie de expectativas que encaminan al oyente hacia el significado del hablante. (Sperber y Wilson 2004: 238)

Los autores, entonces, se distancian de la teoría griceana en los puntos en los que consideran que no brinda explicaciones satisfactorias acerca de otros fenómenos pragmáticos; en este caso, los autores rechazan que el principio de cooperación y las máximas de la conversación sean los ejes inamovibles que rigen la comunicación; en cambio, le otorgan el lugar preponderante al principio de relevancia:

La tesis central de la teoría de la relevancia es que las expectativas de cumplimiento de la máxima de relevancia que suscita un enunciado deben resultar tan precisas y predecibles que guíen al oyente hasta el significado del hablante. Su objetivo es explicar en términos cognitivos razonables a qué equivalen esas expectativas de relevancia, y cómo éstas pueden contribuir a una visión empírica aceptable del proceso de comprensión. (Sperber y Wilson 2004: 239)

Si la capacidad natural del ser humano al procesar una serie de informaciones lo obligan a maximizar la relevancia, esto se convierte en un mecanismo con el cual un hablante no sólo intercambia información, sino que también, a través de esta interacción puede influir e incluso manipular el estado mental de su interlocutor. Sperber y Wilson definen este proceso como una comunicación ostensivo-inferencial, la cual implica dos tipos de intenciones: intención informativa, para transmitir una información al receptor e intención comunicativa, para hacer llegar al interlocutor la intención de transmitir esa información. Por lo tanto, el estímulo ostensivo se produce con el único propósito de acaparar la atención del interlocutor.

Como regla general, en la comunicación verbal el oyente llega a una interpretación satisfactoria siempre siguiendo el principio del mínimo esfuerzo; con esto intuirá el significado del mensaje del emisor. La comunicación verbal alcanza un grado más alto de comprensión sin recurrir al mayor esfuerzo. También es posible que otras formas de expresión puedan llevar consigo un mayor esfuerzo en el proceso de comprensión. Esto sucede en muchas ocasiones con la ironía verbal, ya que el contenido explícito de un enunciado puede ir más allá de lo literal, evocando diversas implicaturas. $Y$ es en este punto precisamente en el cual abordaremos el tema de nuestra investigación, ya que la teoría de la relevancia considera que el procedimiento de interpretación de la información explícita está dominado por este principio, es decir, la mente del ser humano tiende a procesar estas implicaturas contenidas en los mensajes literales, seleccionando lo más relevante y dotándolos de una significación específica. Este procedimiento es en la 
teoría de la relevancia el proceso de comprensión, en el que el papel activo del hablante y el oyente se centra no sólo en codificar y descodificar los signos lingüísticos emitidos, sino construir significados con los elementos relevantes para ambos.

Muy importante es enfatizar que el tema de la interpretación de la ironía como uso impreciso del lenguaje en la teoría de la relevancia se aleja también de la postura de Grice; principalmente, al ser considerada la teoría griceana como una teoría veritativa, los usos imprecisos del lenguaje representan violaciones para sus máximas, y por su lado, la teoría de la relevancia se esfuerza por tomarlas en cuenta de otra manera:

Dadas sus similitudes intuitivas con la metáfora y la hipérbole, sería tentador analizarlas, al igual que los tropos, como violaciones abiertas (burlas) de la máxima de sinceridad, producidas para guiarnos hacia la búsqueda de una implicatura relacionada (en este caso una versión encubierta de lo dicho). El problema es que estos usos imprecisos del lenguaje no son generalmente percibidos como violaciones de la máxima de sinceridad. (Sperber y Wilson 2004: 258)

Las llamadas figuras retóricas o literarias y la ironía, son consideradas como violaciones de las máximas en la teoría de Grice. Esto, sin embargo, presenta varias limitantes para su análisis. Las imprecisiones al hablar, al igual que muchos tropos como la metáfora y la hipérbole, según los autores, no logran ser descritos en la teoría de Grice. Aunque, aparentemente, la propuesta de Grice es acertada para analizar estos fenómenos pragmáticos, la apuesta de la teoría de la relevancia, ante esta cuestión, se desmarca de la máxima de sinceridad y se ciñe a la expectativa de relevancia para explicar estos fenómenos. Esta tesis es fundamental para el estudio de la ironía, la cual es considerada en este trabajo como un suceso con efectos cognitivos, y por lo tanto, susceptible de usarse como un medio argumentativo en el discurso. Si para Grice este proceso cognitivo consistía en comprobar la interpretación literal, la cual será sustituida por una interpretación figurativa si la literal viola la máxima de sinceridad, para la teoría de la relevancia, el efecto cognitivo inmediato no pasa por el proceso de selección de Grice, pues no hay ninguna ley que obligue a que el significado literal siempre sea el primero en ser procesado, con lo que la ironía se convierte en un medio muy efectivo para la comunicación, y por ende, desde nuestra perspectiva, para la argumentación, ya que al ser un proceso tan inmediato, se encuentra inmerso en el lenguaje común más de lo que los análisis meramente retóricos lo considerarían.

La aportación teórica de los postulados de Sperber y Wilson (1981, 1992, 2004), es que no colocan la ironía, la metáfora y la hipérbole en una misma categoría inamovible, como efectivamente hizo Grice, sino que las describen como un fenómeno aparte por considerar que contiene características muy particulares, por ejemplo, su espontaneidad, y la que los autores reconocen como la más esencial: su uso ecoico. En la teoría de la relevancia la ironía funciona como un eco que comunica una actitud ante lo dicho; para poder entender lo que una persona pretende expresar ante las aseveraciones o ideas de alguien más, el interlocutor debe reconocer lo que se comunica e identificar una actitud 
psicológica diferente del emisor; estas actitudes psicológicas son muy diversas, dependiendo de la postura que el emisor quiera transmitir, estando a favor de aquello a lo que evoca, estando en contra de ello, o bien mostrándose dudoso, burlón o incluso apático:

Un enunciado es ecoico cuando alcanza la mayor parte de su relevancia no mediante la expresión de las propias opiniones del hablante, ni informando de los enunciados o pensamientos de otro, sino expresando la actitud del hablante hacia las opiniones que atribuye tácitamente a otro. (Sperber y Wilson 2004: 263).

Entendida así la ironía, la teoría de la relevancia supone una herramienta muy fructífera en el análisis y la descripción de los enunciados irónicos en las lenguas y en sus producciones de textos:

Una consecuencia de este análisis es que la ironía supone una habilidad metarepresentacional de un orden superior al de la metáfora. Según la teoría de la relevancia, la interpretación de enunciados ecoicos en general supone la habilidad para reconocer que el hablante está pensando, no directamente en un estado de las cosas, sino en otro pensamiento o enunciado que atribuye a alguien más. (Sperber y Wilson 2004: 265)

\section{Los ecos irónicos en Todos santos, día de muertos}

En este apartado nuestro objetivo es mostrar cómo la teoría de la relevancia constituye un marco teórico bastante viable para el análisis y la descripción de los enunciados irónicos. Particularmente, hemos seleccionado el ensayo titulado Todos santos, día de muertos en el cual Octavio Paz hace una observación minuciosa sobre la identidad del mexicano, y aborda las cuestiones sobre cómo es su relación con la vida y la muerte, y cómo se puede leer esta relación en la celebración del día de los muertos. Tratamos pues de identificar algunos fragmentos en el ensayo que pueden interpretarse como irónicos y justificamos por qué pueden ser leídos de esta manera.

(1) Todos santos, día de muertos.

Este enunciado hace eco de una celebración muy conocida dentro de la tradición cristiana: se trata del día de todos los santos, que se celebra el 1 de noviembre de cada año. El título del texto se presenta como una interpretación de segundo grado, ya que está ligado a la siguiente aseveración:

(2) El 1 de noviembre la Iglesia celebra el día de todos los santos. 
El comentario irónico aquí se puede interpretar de la siguiente manera: en primer lugar, hay en los dos enunciados una diferencia de carácter semántico: En (1) santos, tiene el funcionamiento de adjetivo calificativo en segunda persona plural (Todos ustedes / son / somos santos). En el enunciado fuente (2), santos tiene una función de sustantivo: los santos. Para dar a su ensayo desde el comienzo el tono crítico, Octavio Paz hace referencia al día en el que las iglesias cristianas celebran solemnemente a los difuntos que se han convertido en santos. En el título del ensayo, Octavio Paz ya no manifiesta el supuesto de que se celebra el día de todos los santos, sino que cambia el significado utilizando santos como adjetivo, es decir hace una interpretación de segundo grado y la vincula con el carácter del mexicano en estas festividades. Como bien es sabido, el día de muertos que se celebra en México justamente el día 2 de noviembre, es una festividad producto del sincretismo cultural, que originalmente conjunta el carácter ritual de los pueblos indígenas con la tradición cristiana de conmemorar, esta vez, a los difuntos fieles a la iglesia. Sin embargo, ante los ojos de Paz, el mexicano moderno ha perdido cualquier tipo de conexión ritual con la festividad y, en cambio, la aprovecha para descargar sus comportamientos más irracionales, por lo que la fiesta se vuelve un lugar y un espacio en el tiempo para aminorar sus propios complejos e inseguridades. En este sentido, decir "todos santos", marca ya la postura crítica e irónica del autor, pues si se entiende la palabra santo como alguien perfecto, virtuoso y puro -de acuerdo con las virtudes teologales y los mandamientos cristianos- el mexicano es todo menos un santo, cuando se sumerge en los excesos de la fiesta. Para ir entendiendo más a fondo el sentido irónico del título, vamos a continuar con la observación de los siguientes fragmentos de este ensayo, que condensan perfectamente la postura del literato:

(3) El mexicano obstinadamente cerrado ante el mundo y sus semejantes, ise abre ante la muerte? La adula, la festeja, la cultiva, se abraza a ella, definitivamente y para siempre, pero no se entrega ( $\operatorname{Paz} 1983: 46)$.

La interpretación de (3) como un fragmento irónico, tiene sentido gracias a que podemos identificar un eco en la pregunta ise abre ante la muerte? la cual hace eco a la afirmación común de que "El mexicano se abre ante la muerte", es decir, se hace alusión a la idea imperante de que la cultura mexicana tiene una relación peculiar con la muerte, pues se dice comúnmente que el mexicano se ríe de la muerte, o no la toma tan en serio porque la considera como algo cercano. Hacer eco a esta idea, colocándola como un cuestionamiento, evidentemente nos hace inferir que el autor pone en duda e incluso rechaza tal idea. El comentario irónico se cierra, cuando Octavio Paz afirma que, aunque aparentemente el mexicano tiene una relación cercana con la muerte, esto no es más que una simple fachada, pues en realidad el mexicano "no se entrega". En este caso, los signos de interrogación, el cuestionamiento, es la marca que el locutor utiliza para llamar la atención, por lo que la pregunta genera una expectativa de relevancia en el oyente. 
Podemos mostrar un ejemplo más:

(4) Pero un pobre mexicano icómo podría vivir sin esas dos o tres fiestas anuales que lo compensan de su estrechez y de su miseria? (Paz 1983: 36)

En (4), volvemos a encontrarnos con un tono irónico. Aquí podemos identificar dos ecos: En primer lugar, pobre mexicano, es una interpretación irónica de una de las problemáticas que afectan al país: la pobreza y la falta de recursos para subsistir, en este sentido el enunciado original bien podría ser: El mexicano es pobre. Para ironizar con este supuesto, Paz elige la forma modal pobre mexicano, en la que el énfasis está precisamente en la actitud compasiva que alguien podría mostrar para con el sujeto. El segundo segmento completa el comentario irónico del autor, con una pregunta, que igualmente hace eco al supuesto de que para el mexicano la fiesta es un ritual que ocupa un lugar primordial no sólo en la vida social del mismo, sino en la constante afirmación de su identidad nacional. Octavio Paz cuestiona irónicamente este supuesto, pues la tesis del autor apunta a la conclusión de que precisamente este ritual es para el mexicano algo ya vacío de significación; para el autor, el hecho de que el mexicano sea asiduo a las celebraciones masivas tiene que ver con que estas representan un paliativo para la soledad, provocada por sus diversos complejos e inadaptación, como se puede leer en las líneas que siguen:

Las fiestas son nuestro único lujo [...] En esas ceremonias -nacionales, locales, gremiales o familiares- el mexicano se abre al exterior. Todas ellas le dan ocasión de revelarse y dialogar con la divinidad, la patria, los amigos o los parientes. Durante esos días, el silencioso mexicano silba, grita, canta, arroja petardos, descarga su pistola en el aire. Descarga su alma. (Paz 1983: 37)

Por otro lado, podemos localizar otras ironías que son un poco más sutiles, en las que el autor también utiliza como referentes aspectos de la historia y de las tradiciones mexicanas:

(5) Ciertos días, lo mismo en los lugarejos más apartados que en las grandes ciudades, el país entero reza, grita, come, se emborracha y mata en honor de la Virgen de Guadalupe o del General Zaragoza (Paz 1983: 35)

En este fragmento, el tono irónico puede ser interpretado como una reprobación de las actitudes frenéticas de los mexicanos que Paz describe, quienes se justifican en la celebración de una festividad, sea religiosa o patriótica, para llevar a cabo sus insensatas acciones. El autor hace eco de las celebraciones en honor de la Virgen de Guadalupe, una de las fechas más importantes en el calendario de los mexicanos, y por otro lado, de la celebración del día 5 de mayo, dedicado al General Zaragoza, quien es un personaje 
importantísimo dentro del nacionalismo mexicano, ya que fue él quien venció al poderoso ejército francés en la mítica batalla de Puebla. Este ejemplo es interesante porque, curiosamente se puede encontrar una interpretación irónica que manifiesta dos actitudes por parte del autor. Por un lado, el autor se disocia de la idea de que los comportamientos de los mexicanos durante estas fiestas son solemnes o cívicos (como idealmente debería ser). Evidentemente, reprueba el hecho de embriagarse y matar, y al mismo tiempo lo contrasta con otras actividades normalmente pacíficas como rezar o comer. Pero, en esta crítica también se burla de la supuesta solemnidad de las conmemoraciones, ya sean religiosas o nacionalistas, que a todos los mexicanos nos han enseñado a rememorar con respeto y seriedad. En pocas palabras, Octavio Paz no sólo reprueba el frenesí de los participantes de la fiesta, sino que también pone en duda el supuesto respeto que todos los mexicanos tenemos para con estas celebraciones, las cuales son nuevamente espacios para disfrazar los complejos y descargar los problemas de sus asistentes:

Cada año, el 15 de septiembre a las once de la noche, en todas las plazas de México celebramos la fiesta del Grito; y una multitud enardecida efectivamente grita por espacio de una hora, quizá para callar mejor el resto del año [...] Nuestra pobreza puede medirse por el número y suntuosidad de las fiestas populares. Los países ricos tienen pocas: no hay tiempo ni humor. Las masas modernas son aglomeraciones de solitarios (Paz 1983: 35).

Con su ironía, Paz pretende verbalizar el absurdo que hay en matar en honor al santo o héroe que se festeja. De tal manera, lo que el autor transmite en (5) son sus supuestos e interpretaciones sobre tales fenómenos, y su relevancia está en que intenta, por medio de éstos, modificar el contexto cognitivo del lector, quien deberá interpretar esta información como una crítica no sólo a tales comportamientos, sino a los supuestos generalizados de que el mexicano acude a festejar a la Virgen de Guadalupe por la fe que le tiene, o bien a celebrar una festividad de la nación por considerarla importante para la república.

Por último, mostraremos algunos ejemplos de ironías que se presentan como ecos de refranes populares. En el siguiente ejemplo, el literato aborda el tema del carácter ritual de la fiesta y lo contrasta con los costos que éstas generan:

(6) Porque con el derroche se espera atraer, por contagio, a la verdadera abundancia.

Dinero llama dinero (Paz 1983: 38).

Aquí, el refrán utilizado, "dinero llama dinero", debe entenderse no como reafirmación del sentido original del mismo, sino como una actitud de rechazo y de crítica ante el derroche. Con esta mención, el autor está mostrando también lo absurdo que es gastar el poco dinero que se tiene en un festejo, mientras el resto del año el mexicano vive con carencias. Sin embargo, como se ha aclarado antes, Octavio Paz 
analiza esta conducta como un mecanismo de defensa. El autor retoma el refrán popular para ironizar sobre la creencia de que quien invierte recibirá ganancias al por mayor. En este caso, hay una burla pues la mayoría de los mexicanos regresan a su realidad y con ello a enfrentar sus carencias materiales, una vez terminada la gran celebración. En el siguiente fragmento, sucede algo muy similar. Octavio Paz habla nuevamente sobre la relación que existe entre el mexicano moderno y la vida y la muerte:

(7) La muerte es intransferible, como la vida. Si no morimos como vivimos es porque realmente no fue nuestra la vida que vivimos: no nos pertenecía como no nos pertenece la mala suerte que nos mata. Dime cómo mueres y te diré quién eres (Paz 1983: 42).

Hay un refrán popular al que se hace alusión, y que es un ejemplo de intertextualidad o de cita encubierta: "Dime con quién andas y te diré quién eres". Para construir su comentario irónico en (7), Paz modifica el refrán original y lo relaciona no con las amistades, sino con el tipo de muerte. Así, al escribir "Dime cómo mueres y te diré quién eres", el autor muestra una actitud crítica ante la relación de causa-efecto que, según el escritor, tiene el mexicano contemporáneo con la muerte:

Nuestra muerte ilumina nuestra vida. Si nuestra muerte carece de sentido, tampoco lo tuvo nuestra vida. Por eso cuando alguien muere de muerte violenta, solemos decir: "se la buscó". Y es cierto, cada quien tiene la muerte que se busca o la muerte que se hace. Muerte de cristiano o muerte de perro son maneras de morir que reflejan maneras de vivir. (Paz 1983: 42)

Con los ejemplos anteriores, hemos intentado demostrar cómo la teoría de la relevancia ofrece un nuevo enfoque de análisis de la ironía que va más allá de considerarla como antífrasis. Con la noción de interpretación de eco, hemos podido analizar algunos fragmentos de este ensayo que para muchos otros críticos y teóricos pasarían desapercibidas, o bien no podrían ser considerados como ironías de acuerdo a las posturas tradicionalistas.

\section{Teoría de la argumentación: ironía y polifonía}

En su obra titulada La argumentación en la lengua, publicada por primera vez en 1983, Anscombre y Ducrot proponen una postura estructuralista que considera la lengua como un medio para construir discursos en el marco de la actividad argumentativa: "Anscombre y Ducrot mantienen que no se argumenta con la lengua, sino en la lengua. Son los propios elementos lingüísticos, y no los hechos que pudieran representar, los que condicionan por su significación la dinámica discursiva” (Portolés 1988: 73). La teoría de 
la argumentación contempla varios aspectos lingüísticos, por medio de los cuales se pueden describir las dinámicas argumentativas que tienen lugar en el texto. Fuentes $y$ Alcaide (2007) se adscriben a la postura de Anscombre y Ducrot al considerar que el fin de todos y cada uno de los textos producidos tiene que ver precisamente con este carácter argumentativo, y el entramado textual será entonces una especie de instructivo para guiar al lector y llevarlo de un argumento a una conclusión determinada y de unas conclusiones a otras:

Todo texto tiene la intencionalidad de conseguir unos objetivos que mantienen en el punto de mira al interlocutor, como figura a la que hay que conseguir atraer a nuestro terreno por un medio u otro. En este sentido, la afirmación de estos autores debemos entenderla de una forma más amplia: la argumentación en el lenguaje. Es decir, lo argumentativo es una característica inherente al lenguaje mismo, entendido como capacidad de comunicación verbal. (Fuentes y Alcaide 2007: 11)

El estudio de la argumentación en la comunicación verbal, por lo tanto, trae consigo nuevas nociones y perspectivas, desde las cuales se pueden analizar diversas situaciones comunicativas como la ironía, Para ello, es menester observar el proceso en el que aparece la ironía bajo la lupa de la teoría de la polifonía.

Ducrot (1986), considera que la enunciación irónica debe ser analizada como un tipo de polifonía, puesto que la esencia de un enunciado irónico radica en el hecho de que el locutor muestra su actitud ante el punto de vista que expone, disociándose de éste y otorgándole un carácter absurdo, reprobable o burlón:

De esta forma, en un discurso irónico el locutor presenta la enunciación como producto del punto de vista de un enunciador, distinto a él, con el que no se siente identificado. Se trata de una posición absurda directamente expresada en la enunciación, pero no imputada al locutor, sino al enunciador, cuya perspectiva expresa. (Fuentes y Alcaide 2007: 71)

Por lo tanto, el carácter polifónico del enunciado precede a la ironía, y lo que marca a un enunciado como irónico es que expresa de manera implícita esta contraposición entre el punto de vista de un enunciador y del locutor:

La peculiaridad de la enunciación irónica es que ambos puntos de vista (ambos discursos) no se oponen de manera semántica, sino implícitamente. El locutor no los organiza y confronta mediante correctores y operadores argumentativos, sino que la polémica resulta de las valoraciones intrínsecas a las expresiones en conflicto. (Bruzos Moro 2009: 9)

Algunas de las fuentes que Ducrot retoma para construir su propia perspectiva sobre este fenómeno de la comunicación verbal, son Berredonner (1981) y justamente el trabajo de Sperber y Wilson (1981) dedicado a analizar la ironía como eco o mención: 
La expresión enunciado ecoico (o eco) es un concepto similar al del enunciador, que procede de la teoría de la relevancia. Los enunciados ecoicos son discursos evocados. Según Wilson y Sperber (2002), son representaciones de estados mentales o enunciados atribuidos a otros o metarepresentaciones (representaciones contenidas en otras representaciones). (Rajić 2012: 296)

No obstante, Ducrot no se adscribe totalmente a las tesis de Sperber y Wilson, pues considera que la noción de mención propuesta inicialmente en la teoría es bastante problemática:

Ahora bien, con este sentido del verbo mencionar la tesis de Sperber y Wilson es prácticamente inadmisible, porque nada tiene de irónico comunicar que alguien ha pronunciado un discurso absurdo. Para que nazca la ironía es preciso que desaparezca toda marca de transmisión, hace falta "hacer como si" este discurso fuera realmente pronunciado, y pronunciado en la enunciación misma. Idea que procuro plasmar diciendo que el locutor "hace oír" un discurso absurdo, pero que lo hace oír como si fuera el discurso de otro, como un discurso distanciado. (Ducrot 1986: 215).

La solución que encuentra Ducrot a lo que él considera un concepto problemático en la teoría de la relevancia está precisamente en la distinción entre el rol del locutor y los enunciadores, por lo que la ironía es definida por el autor de la siguiente manera:

Hablar de manera irónica equivale, para un locutor L, a presentar la enunciación como si expresara la posición de un enunciador $\mathrm{E}$, posición que por otra parte se sabe que el locutor $\mathrm{L}$ no toma bajo su responsabilidad y que, más aún la considera absurda. Sin dejar de aparecer como el responsable de la enunciación, $L$ no es homologado con $\mathrm{E}$, origen del punto de vista expresado en la enunciación. (Ducrot 1986: 215)

Principalmente, para detonar la ironía, dice Ducrot, el locutor debe presentar su enunciado como una crítica, una burla o mostrar una actitud de escepticismo, el locutor tendrá que enviar la señal de que el oyente deberá optar por una interpretación irónica. Aunque al prestarle espacio en el enunciado a otro enunciador, y que por un momento parezca que el locutor se adhiere a este punto de vista, inmediatamente éste se distancia del enunciador al que evoca.

En conexión con el carácter no informativo de la lengua, y muy similar a lo propuesto por Sperber y Wilson con su teoría de la relevancia, el modelo de Ducrot demuestra que la ironía, no es una simple sustitución de significaciones, no la coloca en los cajones de lenguaje literal o figurado, y ante todo, con su perspectiva polifónica reafirma la idea de que no se trata de ninguna desviación del lenguaje. 


\section{Enunciados irónicos en Nueva España: orfandad y legitimidad}

En este breve ensayo, Octavio Paz se ocupa de la forma en que se ha concebido y estudiado la época colonial en México, sobre todo hace una introspección de cómo y bajo qué circunstancias este momento del pasado ha sido reconstruido por los historiadores. En este proceso, el literato encuentra que la conexión del mexicano moderno con la Nueva España guarda un cúmulo de contradicciones. Por un lado, se ha mostrado desde las esferas intelectuales un desdén y una negación a esta etapa de la historia, y por otro lado, otros tantos escritores e historiadores han buscado reivindicarla, argumentando que en ella se encuentran los orígenes de la idea de la mexicanidad actual. Sin embargo, para Octavio Paz, estas complicaciones tienen su origen en las contradicciones mismas que acompañaron la fundación de la Nueva España, y por consiguiente, la fundación de México como hoy lo conocemos. A continuación trataremos de describir cómo se constituyen semánticamente algunos de estos comentarios irónicos y cómo funcionan argumentativamente dentro del texto. Proponemos a continuación un primer ejemplo, en el que Octavio Paz hace referencia a la esencia y los métodos de la historia como ciencia humana:

(1) Los hechos históricos no están gobernados por leyes o, al menos, esas leyes no han sido descubiertas. Todavía están por nacer los Newton y los Einstein de la historia. (Paz 1983: 391).

En el fragmento anterior bien podrían reconocerse los siguientes enunciadores: E1 y E2 que corresponden a "Los hechos históricos están gobernados por leyes" versus "No están gobernados por leyes". Para orientar argumentativamente el punto de vista del enunciador E2, el locutor recurre a una locución adverbial al menos, que en el discurso funciona como operador para fortalecer la idea anterior y para proseguir el discurso con dos enunciadores más que enfatizan la salvedad del asunto: E3 “Han sido descubiertas leyes que gobiernan los hechos históricos" y E4 que se opone a este enunciador. Octavio Paz, utiliza a continuación el enunciado irónico: “Todavía están por nacer los Newton y los Einstein de la historia", un punto de vista en el que vuelven a aparecer dos enunciadores: un E5, que afirma "Los Newton y Einstein de la historia no han nacido", y un E6 marcado por todavía, del cual precisamente el autor se disocia, mostrándose con una actitud escéptica.

De esta manera, en (1) se puede explicar con un ejemplo lo que es y cómo funciona una ironía desde la teoría de la enunciación polifónica en la cual, según las palabras de Bruzos Moro:

En definitiva, lo crucial es que exista un contraste entre la verdadera opinión del locutor y la que se expresa literalmente en el enunciado. Además, para que este contraste suponga la disociación propia de la ironía, ha de servirse a la audiencia de 
manera implícita: el locutor simula confirmar el punto de vista del enunciador, al que en realidad se opone y, frecuentemente, ridiculiza. (Bruzos Moro 2009: 8)

Se podría afirmar que los siguientes ejemplos que vamos a presentar, en mayor o menor grado, siguen también esta línea. En estos fragmentos, el tema al que se refiere Octavio Paz gira en torno a la supuesta prefiguración del nacionalismo mexicano en la literatura novohispana; decimos supuesta, porque como veremos a continuación, Paz se opone a esta tesis, argumentando que los movimientos culturales surgidos en tal época fueron únicos en su tipo. Veamos ahora cómo construye Octavio Paz su argumentación haciendo uso de la ironía, nuevamente, intentaremos describir los enunciadores que interactúan en este enunciado:

(2) Convertir a una poetisa barroca en un autor nacionalista no es menos extravagante que haber hecho del tlatoani azteca, Cuauhtémoc, el origen del México moderno (Paz 1983: 396).

En (2), gracias al comparativo negativo no es menos extravagante que, se presenta una opinión por parte del locutor que implícitamente califica y equipara a ambos enunciadores como absurdos. En este caso, el locutor pone en duda la veracidad tanto de E1, que afirma que "Sor Juana es precursora del nacionalismo mexicano" como de E2 que plantea que "Cuauhtémoc es el origen del México Moderno". Ambas ideas son evocadas por Octavio Paz con la intención de rebatirlas, y con este fin el locutor del enunciado trae a colación estos enunciadores no para adherirse a ellos sino para ponerlos en cuestionamiento. La reflexión a la cual el autor del texto quiere llevar al lector es: "Ni Sor Juana, ni Cuauhtémoc se pronunciaron a favor del nacionalismo mexicano". Sin embargo, como podemos ver, en (2) hay una ironía en la que si bien el autor pone en escena a estos enunciadores y efectivamente se disocia de ellos, hay un menor grado en el carácter implícito de ésta. Quizás la clave se encuentra en la elección del locutor de hacer uso del adjetivo extravagante, el cual si bien podría tener una carga negativa, es una elección estratégica del locutor para evitar utilizar el calificativo absurdo, y con ello eliminar todo tipo de significado implícito. Esta diferencia de gradación en el significado implícito se puede notar también en (3), donde Octavio Paz continúa su tono irónico sobre el mismo tema:

(3) Incluso críticos perspicaces como Alfonso Reyes y Pedro Henríquez Ureña descubrieron en las comedias de Ruiz de Alarcón y en los sonetos y décimas de Sor Juana no sé qué esencias mexicanas. (Paz 1983: 396)

No obstante, y esta es una de las problemáticas que se le puede adjudicar a la teoría de la enunciación polifónica, es que, en muchos casos la tarea de ubicar, demarcar y describir a los enunciadores así como la manera en que éstos se oponen o se 
complementan unos a otros para llegar a determinada conclusión, se va volviendo más complicada. En muchos casos la ironía se presenta gracias a determinadas marcas (signos de exclamación, interrogación, comillas, etc.) o, contrariamente a los postulados de la teoría de la argumentación en la lengua, como un significado implícito resultado de la información contextual.

Este es el caso de (3) en el que Octavio Paz hace referencia a las ideas de Reyes y Henríquez Ureña, pero añadiendo el modo irónico con una expresión como lo es "no sé qué". En este caso, es más difícil demostrar que el locutor se disocia implícitamente del enunciador, ya que Paz recurre a una cita indirecta con lo que disminuye el grado de responsabilidad y aceptación de estas tesis por parte del locutor. No obstante, es difícil también negar el tono irónico con el que el literato se opone a estas ideas. Al anteponer el "no sé qué" a "esencias mexicanas" la disociación se hace explícita gracias a que el "no sé qué" semánticamente resta relevancia y disminuye la fuerza argumentativa de "esencias mexicanas". A pesar de ello, nos atrevemos a afirmar que no por ello disminuye el carácter irónico del enunciado.

Aunque, ciertamente, es factible analizar muchos de los casos de ironía verbal desde la teoría de la enunciación polifónica, es verdad también que en su aplicación a muchos otros casos el investigador puede, si no morir en el intento, tener bastantes limitaciones al querer encontrar y describir con precisión a los enunciadores que aparecen en los enunciados; aun así, la enunciación polifónica sí es una opción viable para analizar determinado tipo de enunciados irónicos, y quizás su aportación más interesante a la pragmática es que desde esta perspectiva la ironía existe y funciona gracias a su inferencialidad, como bien describe Bruzos Moro (2009: 8): "La ironía tiene esta peculiaridad: ha de sugerirse, no decirse. La ironía tiene un efecto mejor cuanto más elusiva sea, mientras que su naturaleza polémica es demasiado obvia, demasiado descarada, resulta vulgar e incluso menos irónica".

\section{Conclusión}

En los fragmentos de los ensayos analizados, gracias a estas dos perspectivas teóricas, podemos evidenciar que Octavio Paz utiliza diversos tipos de ironía para transmitir sus reflexiones sobre los temas que le ocupan, y con ello logra comunicar de manera más efectiva estas ideas al lector. La mayoría de estas ironías son muy sutiles, pero forman parte importante de la estructura argumentativa del texto, pues generan efectos importantes en el ámbito cognitivo del lector. Más importante aún es que se muestra que la ironía, como recurso argumentativo, puede presentarse en diversas formas y grados, dejando atrás la idea de la ironía como antífrasis. 


\section{BIBLIOGRAFÍA}

Anscombre, Jean Claude, y Oswald Ducrot. La argumentación en la lengua. Madrid: Gredos, 1994. Impreso.

Berrendonner, Alain. Elementos de pragmática lingüistica. Buenos Aires: Gedisa, 1981. Impreso.

Bruzos Moro, Alberto. "La polifonía". Leonor Ruiz, Leonor Ruiz Gurillo y Xose A. Padilla García (eds.), Dime como ironizas y te diré quién eres: Una aproximación pragmática a la ironía. Frankfurt: Peter Lang, 2009: 45-64. Impreso.

Ducrot, Oswald. Slovenian Lectures. Introduction into argumentative semantics. Ljubljana: Pedagoški Institut, 2009. Print.

Fuentes Rodríguez, Catalina, y Esperanza Alcaide Lara. La argumentación lingüistica y sus medios de expresión. Madrid: Arco libros, 2007. Impreso.

Grice, Herbert Paul. "Lógica y Conversación". Luis Valdés Villanueva (ed.), La búsqueda del significado. Lecturas de filosofía del lenguaje, Universidad de Murcia: Editorial Tecnos, 1991: 511-530. Impreso.

Paz, Octavio. Los signos en rotación y otros ensayos. Madrid: Alianza tres, 1983. Impreso.

Portolés, José. "La teoría de la argumentación en la lengua y los marcadores del discurso". María Antonieta Martín Zorraquino y Estrella Montolío (eds.), Los marcadores del discurso. Teoría y análisis, Madrid: Arco libros, 1998: 71-92. Impreso.

Rajić, Jelena. “Polifonía y formas verbales”. Verba hispanica, 20.1 (2012): 295-304. Impreso.

Sperber, Dan, y Deidre Wilson. "Irony and the Use-Mention Distinction". Peter Cole (ed.) Radical Pragmatics, New York: Academic Press, 1981: 295-318. Print.

—. "On verbal irony". Lingua, 87 (1992): 53-76. Print.

—. "La teoría de la Relevancia”. Revista de Investigación Lingüistica, 7 (2004): 237-286. Impreso. 